\title{
Dossiê
}

\section{LEITURA DE BEBÊS ${ }^{1}$}

RESUMO

$\mathrm{Na}$ clínica com a primeira infância se intervém não só por meio da escuta, mas fundamentalmente por meio de uma leitura - leitura que ope$\mathrm{ra} \mathrm{em}$ relação às produções do bebê e também em relação ao modo de seus pais colocarem em ato seu discurso nos cuidados que lhe dirigem. Isto leva a considerar de que modo o olhar do clínico se situa diante do sintoma dado a ver no corpo do bebê, diferenciando seu lugar na observação de bebês do que ocupa em uma clinica que intervém por meio de uma leitura.

Descritores: bebês; psicanálise; letra; estimulação precoce

\author{
Julieta Jerusalinsky \\ Manoel Tosta Berlinck
}

(

uando um bebê apresenta um sintoma que coloca em risco a sua constituição psíquica, o sofrimento comparece em sua organização corporal e na realização de suas produções. ${ }^{2}$ Trata-se, portanto, de um sintoma que é dado a ver.

Entendemos o dar a ver não no sentido do que se quer mostrar, mas do que comparece, do que se manifesta do sujeito no movimento, no tônus, em sua produção rítmico-temporal, e que, portanto, comparece na organização das funções corporais para além de suas intenções.

Esta é uma primeira questão de central importância a levar em conta e que marca uma especificidade da clínica com bebês: que o padecimento compareça pela via do dado a ver.

Marcamos isso porque, se há algo próprio no método psicanalítico, é a escuta que se produz da

- Psicanalista, doutoranda em psicologia clínica e pesquisadora vinculada ao Laboratório de Psicopatologia Fundamental da Pontifícia Universidade Católica de São Paulo, membro do Centro Lydia Coriat e da Associação Psicanalítica de Porto Alegre

(APPOA).

- - Sociólogo, psicanalista, Ph.D. pela Cornell University, professor do Programa de Estudos Pós-Graduados em Psicologia Clínica da Pontifícia Universidade Católica de São Paulo, diretor do Laboratório de Psicopatologia Fundamental da Pontifícia Universidade Católica de São Paulo. 
associação livre do paciente, posta em causa a partir do sintoma, que produz nele sofrimento.

A inauguração da psicanálise implica justamente essa mudança de eixo de intervenção: passando da ordem do ver, do assistir ao espetáculo das apresentações de histéricas consagradas por Charcot, ao escutar a fala dessas pacientes, considerando que tal fala está inexoravelmente atrelada ao padecimento que as acomete no corpo.

Freud nos mostra como, ao desdobrar por meio da fala em transferência a associação que levou à produção do sintoma (com sua série de condensações e deslocamentos), assim como pelas intervenções do analista, é possível produzir deslizamentos de significação que possibilitam mudanças do sujeito em relação ao sintoma.

Sabemos, no entanto, que o modo pelo qual uma criança circula na linguagem não é o mesmo que o de um adulto. Freud (1932/ 1977a) diz isso com todas as letras ao afirmar que para a criança o método da associação livre não tem muita razão de ser.” (p. 181). E isso deu origem a uma série de questões acerca dos métodos na psicanálise com crianças, entre as quais a central proposição de Melanie Klein (1926), de que o brincar está para a psicanálise de crianças como a associação livre está para a psicanálise de adultos.

Contudo, quando intervimos na primeira infância, tal questão apresenta-se de modo ainda mais radical: afinal, como comparece o sujeito em um tempo em que ainda não há fala e em que ainda nem sequer há a possibilidade de um desdobramento do brincar que arme uma extensão simbólica? Justamente porque o sujeito na primeira infância comparece pela produção e organização corporal.

Mas, então, tratar bebês nos lançaria novamente ao campo do visto no corpo e do observável na intervenção?

Uma breve incursão pela história da psicanálise mostra-nos o rastro produzido entre o observável e a primeira infância. É Freud (1909/1977b) mesmo quem primeiramente solicita a alunos e amigos que lhe façam chegar observações acerca da vida das crianças. E é assim, aliás, que o pequeno Hans chega até ele.

Esses questionamentos ocorrem em um tempo em que a aproximação da psicanálise à infância era ainda muito mais mítica que factual, ou seja, vinha se dando ainda muito mais pelo relato das lembranças infantis dos adultos em análise do que pelo tratamento efetivo de crianças - assim sendo, é completamente lícita uma interrogação que vai se produzindo no cerne da psicanálise acerca da pertinente diferenciação entre o sujeito na infância e o infantil do adulto, com seus efeitos para a clínica. ${ }^{4}$ 
É nessa direção que inicialmente é proposto o método de observação direta de bebês, que, em um primeiro momento, surge não como uma intervenção clínica, mas como uma atividade integrante da formação dos analistas. ${ }^{5}$ Segundo as palavras da própria Esther Bick (1964/1967), com o objetivo de ajudar "a compreender o comportamento não verbal da criança e suas brincadeiras, assim como o comportamento da criança que não fala nem brinca." (p. 97, tradução nossa).

Freud (1905/1977c) nos aponta a importância de observar a produção daqueles que ainda não falam apostando que, por meio de tais observações, é possível corrigir uma série de pressupostos errôneos sobre a infância, por exemplo, o da inexistência de sexualidade nos bebês e crianças. No entanto, mostrase bastante reticente no sentido de considerar que a observação de crianças por si só possa levar a algum esclarecimento, chegando a afirmar que "se os homens soubessem aprender com a observação direta de crianças, estes três ensaios poderiam não ter sido escritos." (p. 133). No mesmo texto - Três ensaios sobre a teoria da sexualidade infantil - aponta-nos a necessidade de conjugarmos tais observações ao método psicanalítico.

Mas em que consistiria essa "conjugação" da observação ao método psicanalítico? Ela pode ser tomada de diferentes modos, com conseqüências epistemológicas diversas, segundo situamos o que é dado a ver como acontecimento clínico próprio dos fenômenos contemplados no campo da psicanálise ou como um fenômeno que exigiria uma observação guiada por outros princípios e métodos.

Nesse sentido, é preciso ter em conta que tal método surge em um momento em que está em jogo considerar a psicanálise uma ciência alinhada ou não alinhada aos princípios positivistas. Diante de tal debate, o método de observação de bebês, "ao dar ênfase à observação e à descrição cuidadosa dos fenômenos relacionais", teria, segundo os praticantes desse método, "produzido um deslocamento da psicanálise do lugar de ciência explicativa (de causa-efeito) ao lugar de ciência descritiva, de observação de fenômenos que vão emergindo.” (Mélega, 2001, p. 71).

Produz-se, assim, certa aposta no sentido de estabelecer a psicanálise como uma ciência descritiva, contrapondo, por um lado, observação/descrição e, por outro, psicanálise/interpretação, como se a primeira possibilitasse uma abertura ao fenômeno e a segunda viesse a produzir uma espécie de fechamento em um determinismo interpretativo da causalidade psíquica.

A questão que inevitavelmente surge é até que ponto uma observação enveredada pela via do "registro detalhado" que, como 
se indica, possibilitaria efetivamente uma abertura aos fenômenos ou implicaria uma aposta na tentativa de capturar pela descrição do observável em mínimos detalhes o valor do acontecimento. A observação poderia levar a supor que, se nas origens do sujeito encontramos o infans, aquele que não fala, necessariamente a pesquisa das origens implicaria um novo deslocamento: desta vez, da escuta para o olhar, no qual a observação e, atualmente, com o avanço tecnológico, as sucessivas revisões de material filmado - produziria uma psicanálise que giraria em torno de uma espécie de olhar a posteriori.

Evidentemente a questão não se reduz ao fato de que filmar seja bom ou ruim em si mesmo - pode até mesmo ser valioso em termos de estudo e de registro de evolução clínica. $O$ fato é que, quando se trata de intervir com a constituição do sujeito, de produzir ali uma intervenção capaz de mudar a sua relação com o outro e, portanto, com seu sintoma, de nada nos servem pilhas de filmes, se isso que é dado a ver no corpo do bebê (e capturado na película) não é lido em rede com os significantes que sustentam a existência desse bebê e se tal leitura não opera ali em transferência com os pais e com o bebê. Tudo isso aponta o quanto o método psicanalítico não corresponde nem ao princípio da lógica biunívoca nem ao da lógica descritiva, para a apreensão de seu fenômeno. Talvez se encaixe melhor em uma concepção da complexidade.

Esta é uma questão dura da clínica com bebês, a saber: como se tece, na operação clínica, a significação, e como se operam os desliza- mentos de sentido daquilo que o bebê dá a ver em seu corpo e que os pais dão a ver no exercício de seus cuidados.

Outra via possível para considerar qual o estatuto do dado a ver na clínica com bebês é a de que o dado a ver, assim como o dado a ouvir, ou seja, o gesto ou a entoação da voz são tomados na cena clínica como produções que só podem ser lidas, só cobram alguma significação possível, se consideradas na rede de saber própria do humano, a linguagem. Mais ainda: no recorte que a língua produz ao tecer linguagem e cultura e, mais ainda, no recorte singular produzido na língua pela transmissão parental. É a partir dessa rede que se sustenta a produção do bebê e que esta adquire alguma significação possível para a mãe, na medida em que ela produz uma tradução de ação por linguagem e de linguagem por ação da produção desse bebê que opera sob o fundo de um enigma intraduzível que diz respeito ao desejo que perpassa o laço dos pais com o bebê.

Os bebês estão aí para recordar aos psicanalistas que a dimensão significante não se reduz apenas à palavra falada - como certas vertentes da clínica psicanalítica parecem sublinhar, diminuindo a importância do visto no gesto, na postura e no tônus corporal, ou do ouvido na entoação, esquecendo que ambos são também produções pelas quais o sujeito comparece no ato da enunciação.

É por isso que a interpretação nada opera se reduzida a jogos de palavras que em nada perpassam a organização pulsional do paciente. A letra que se precipita no sintoma im- 
plica, em sua condição de litoral (Lacan, 1971), por um lado o sentido a que se tem acesso pelo jogo significante e, por outro, o sem sentido do gozo, mas é essa borda entre gozo e saber que interessa à intervenção do clínico. E é também por isso que o dado a ver no corpo não tem como estar em uma espécie de dimensão pré-lingüística - afinal, a partir de que ponto os pais interpretam a produção do bebê senão da rede simbólica, do saber que se faz possível pela linguagem?

Indo nessa direção, talvez seja lícito considerar se, por essa dita observação, procurar-se-ia introduzir no campo da intervenção com bebês um correlato da "atenção flutuante" própria da escuta de adultos. Teríamos assim, na clínica com bebês, a importância não de uma observação no sentido fenomênicopositivista, mas do estabelecimento de um tempo de ver diante da manifestação corporal do bebê. Ali o clínico, de modo correlato ao da escuta analítica, produziria uma abertura em que se dá lugar ao comparecimento do sujeito.

Sem irmos muito mais longe, parece-nos que é algo dessa ordem que Freud faz em relação ao menino de um ano e meio, seu neto, que brinca com o carretel. É por tomar tal produção em rede com o discurso parental e com o modo como se coloca em ato nos cuidados dirigidos ao bebê que Freud lê o jogo do Fort-da como uma produção constituinte para esse menino e para o sujeito na infância.

Por sua vez, Winnicott (1941) fala-nos de como, por mais de vinte 
anos, observou os diferentes modos de bebês (com 5 a 13 meses de idade) se portarem diante de uma situação por ele proposta durante a consulta pediátrica de rotina: a de deixar à mesa uma espátula ao alcance da mão do bebê enquanto o bebê permanece, junto à mesa, no colo, sobre os joelhos da mãe. ${ }^{6}$ Ele nos mostra como a produção dos bebês diante de uma manobra de tal simplicidade pode propiciar (usando suas palavras) "uma série de chaves" a respeito da situação psíquica da criança, podendo também ser utilizada para produzir efeitos terapêuticos.

É fundamental esclarecer que Winnicott não se detém na manobra. Ele toma o que o bebê dá ali a ver e faz com que opere clinicamente em relação a uma complexa rede:

- Do lado da mãe, aponta-nos a importância de considerar não só o que ela diz sobre o bebê, mas a reação dela durante a manobra, no sentido de dar tempo e lugar à produção do bebê ou no sentido de suprimi-la (tanto pela via do incentivo de que o bebê pegue a espátula quanto pela proibição) considerando que tal modo de proceder da mãe diante de uma situação tão recortada guarda profunda similitude com o modo de esta proceder com o bebê em seus cuidados cotidianos.

- Do lado do bebê, propõe um cruzamento entre o modo de este comparecer em tal cena e o modo de ele comumente se portar, não só em relação aos objetos, mas no estabelecimento de laços com os outros - familiares e estranhos.

- Levanta ainda a importância de considerar a produção do bebê diante de tal manobra em relação aos sintomas por ele apresentados - sintomas de comparecimento somático tais como asma, diarréia ou dificuldades de deglutição, vômito ou refluxo.

Partilhando ou não da metapsicologia proposta por Winnicott, é interessante destacar que é inegável que ele traz os diferentes elementos implicados na operação clínica que realizamos com bebês: a saber, o que consideramos uma operação de leitura na clínica.

Certamente o olhar e o dado a ver estão profundamente implicados na clínica com bebês. No entanto, consideramos que a intervenção clínica, muito mais que levar-nos ao campo do registro da observação, implica uma operação de leitura.

Em que consiste tal operação de leitura? E de que modo o olhar do clínico fica ali implicado?

Para ler é preciso, sim, ver a letra, mas também é preciso deixá-la cair. Se a letra fascina, se o espetáculo por ela apresentado captura o olhar daquele que a observa, então, torna-se impossível ler. Exemplo disso são as iluminuras utilizadas no início dos textos medievais. Elas consistem em letras tão excessivamente ornamenta- 
das que se tornam ilegíveis. Esse era mesmo o intuito de tais imagens, o de capturar o olhar produzindo um silêncio no leitor antes de iniciar a leitura. A figura do bicho, da planta ou personagem fantástico, ao imaginarizar a letra, captura o olhar e silencia o leitor. Esse é o objetivo das iluminuras no texto medieval, o de produzir um silêncio que precede a leitura do texto, mas também é algo dessa fascinação com a letra imaginarizada que, como aponta Bergès (1991), caracteriza a dificuldade de leitura, pois, quanto mais uma letra está do lado do imaginário, menos legível ela é.

Ora, é porque a letra cai em seu registro imaginário - é porque não contém nela mesma a imagem do que ela significa - que ela remete a outra, e assim permite que opere o enigma simbólico que dá lugar à articulação de uma significação que não se encerra no letra por letra, mas se produz como um après-coup decantado do deslizamento do texto em seu contexto.

De modo análogo, podemos considerar que o sintoma manifesto no bebê, o dado a ver que comparece tomando sua produção e seu corpo, pode levar não só a uma observação, mas dar lugar a uma operação de leitura na clínica. Para dar lugar a tal leitura é preciso que o manifesto seja tomado, antes de mais nada, como um enigma.

Nesse sentido, vale a pena considerar o que implica a noção de manifesto no corpo próprio da primeira infância. Por um lado, implica que o sintoma se coloca em posição privilegiada para ser visto. Ao tomar o corpo e a produção, o sintoma torna-se impossível de ser oculto ou dissimulado - isso é próprio do manifesto, como adjetivo. Contudo, se considerarmos que manifesto, como substantivo, refere-se a uma declaração escrita - declaração, por exemplo, diplomática, dirigida de um Estado a outro - seríamos levados a considerar o quanto o corpo do bebê, que encarna um sintoma, apresenta-se ele mesmo como uma carta, como uma declaração.

O que declara o bebê com o sintoma que se apresenta em seu corpo?

Temos aí um manifesto, sim, mas declarado de modo cifrado.

O sintoma comparece sim, é dado a ver, mas de modo enigmático.

Esse paciente que não fala, se não tolera bem os métodos da associação livre é porque ainda carece do alinhavo simbólico que permite tecer o trabalho do sonho e reconstituir seu percurso no trabalho de análise, mas certamente o sintoma que comparece em seu corpo é uma resposta que se tece em um contexto, o contexto é aqui dado pela rede simbólica na qual está sustentado.

Assim, na clínica com bebês, torna-se central o cruzamento do dado a ver no corpo e da produção do bebê com a escuta do discurso parental e o modo como esse discurso se coloca em ato nos cuidados do bebê, dando lugar a uma operação não só de escuta, mas de leitura na clínica.

Intervir com a primeira infância deixa evidente a não correspondência entre corpo e sujeito, dado que é da boca de outros que teremos que escutar muitos dos significantes cen- 


\section{Dossiê}

trais desse sujeito; é em rede com a sustentação de braços alheios que precisaremos ler o armado postural e tônico do bebê; é em rede com a entoação de voz de sua mãe que precisaremos ler sua possibilidade de modulação emotiva; é em relação à sustentação temporo-espacial feita pelo Outro encarnado do bebê (pela surpresa e antecipação diante de sua produção por parte daqueles que o cuidam) que precisaremos ler a possibilidade do bebê de produzir ou inibir sua ação.

É do discurso posto em ato nos cuidados que lhe são dirigidos que se organizam as suas funções corporais, pois, afinal, o bebê é estrangeiro (na medida em que causa estranhamento aos pais com seus sintomas e produções), mas é profundamente familiar, dado que é da rede significante parental que se recortam inconscientemente para o bebê os traços a partir dos quais ele estabelece sua filiação. Esse recorte está longe de ser uma questão menor e coloca a necessidade de que, ao operar tal leitura, deixemos aberta a brecha entre o bebê fantasmático do discurso parental e o bebê que ali comparece com sua produção - sujeito em constituição -, já que nem sempre há entre um e outro uma relação de saturação, dado que o bebê, ainda que seja com o seu corpo, produz uma resposta na qual se engaja como sujeito, caso contrário seria uma mera vítima passiva do desejo parental.

A operação de leitura clínica implica, nesse sentido, mais que um fechamento de compreensão e saber, uma possibilidade, para o bebê e para seus pais, de deslizar nas significações, 
possibilitando um saber fazer em lugar de ficar capturado no fascínio e estranhamento que o sintoma como espetáculo dado a ver produz.

READING BABIES

\begin{abstract}
When treating a baby, a therapist must intervene not only by listening but mainly by reading. One must read the baby's productions and also the way the parents translate their words into actions when taking care of their infant. This brings about the need to consider the way the therapist looks to the symptom visible in the baby's body. He must act differently when observing babies and when acting in a clinic that intervenes by reading.
\end{abstract}

Index terms: babies; psychoanalysis; letter; early stimulation

\section{LECTURA DE BEBÉS}

\section{RESUMEN}

En la clinica con bebés se interviene no solo por la escucha sino fundamentalmente por una lectura lectura que se opera em relación a las produciones del bebé y también em relación al modo que sus padres colocan em acto su discurso en los cuidados que le dirijen. Esto implica considerar como la mirada del clinico se situa frente al sintoma dado a ver en el cuerpo del bebé, diferenciando su lugar en la observación de bebés del que ocupa en uma clinica que interviene por una lectura.

Palabras clave: bebés; psicoanálisis; letra; estimulación temprana

\section{REFERÊNCIAS BIBLIOGRÁFICAS}

Bergès, J. (1991). A instância da letra na aprendizagem. Boletim da APPOA, 6, 6-10. (1977). O corpo e o olhar do Outro. In Centro Lydia Coriat, Escritos da criança $N^{o}$ 2. Porto Alegre, RS: Centro Lydia Coriat. (Trabalho original publicado em 1988)

Bick, E. (1967). Notas sobre la observación de lactantes en la enseñanza del psicoanálisis. Revista Psicoanálisis, 24 (1), 97-115.
(Trabalho original publicado em 1964) Freud, S. (1977a). Novas conferências introdutórias sobre a psicanálise: conferência 34. In S. Freud, Edição standard brasileira das obras psicológicas completas de Sigmund Freud (J. Salomão, trad., Vol. 22, pp. 167-191). Rio de Janeiro: Imago. (Trabalho original publicado em 1932) (1977b). Análise de uma fobia em um menino de cinco anos. In S. Freud, Edição standard brasileira das obras psicológicas completas de Sigmund Freud (J. Salomão, trad., Vol. 10, pp. 15-158). Rio de Janeiro: Imago. (Trabalho original publicado em 1909)

(1977c). Três ensaios sobre a teoria da sexualidade infantil. In S. Freud, Edição standard brasileira das obras psicológicas completas de Sigmund Freud (J. Salomão, trad., Vol. 7, pp. 129-250). Rio de Janeiro: Imago. (Trabalho original publicado em 1905)

Klein, M. (1926). Princípios psicológicos del análisis infantil. In M. Klein, El psicoanálisis de niños, Vol. 2, pp. 23-34. Buenos Aires: Paidós.

Jerusalinsky, J. (2002). Enquanto o futuro não vem: A psicanálise na clínica interdisciplinar com bebês. Salvador: Ágalma.

Lacan, J. (1971). Lituraterra, aula do seminário 18 , inédito.

Mélega, M. P. (2001). A contribuição de Esther Bick à clínica psicanalítica. Revista Psychê, 5 (7), 69-81.

Winnicott, D. (1941). La observación de niños em uma situación fija: Escritos de pediatria y psicoanálisis, Barcelona: Edictorial Laia.

\section{NOTAS}

1 Este artigo integra o projeto de pesquisa de doutorado, em andamento, realizado junto ao Laboratório de Psicopatologia Fundamental PUC-SP, sob orientação do Prof. Dr. 
Manoel Tosta Berlinck. Parte das questões aqui trazidas foi apresentada no Congresso de Psicopatologia Fundamental, Belém do Pará, 2006, e no Congresso da ABEBE, São Paulo, 2006.

${ }^{2}$ É preciso fazer aqui um pequeno parêntese acerca do que entendemos por realização de produções, uma vez que as contribuições da psicanálise para o campo da estimulação precoce e, portanto, o exercício clínico interdisciplinar com bebês, mostra-nos o quanto as produções instrumentais relativas a psicomotricidade, aquisição da língua, construção do pensamento e hábitos de vida diária só cumprem o seu circuito de realização na medida em que consideradas, não em relação a um índice de desenvolvimento neuromaturacional, pura e simplesmente, mas no modo de comparecerem no laço com os outros. Nesse sentido, não dá da mesma saber pular em um pé só, realizando essa ação de modo estereotipado e usá-la para brincar de saci-pererê. Para tomar uma produção própria dos primeiros meses, não dá na mesma fazer, em torno dos 8 meses "ma, ma, ma" de modo ensimesmado e dirigir ao outro tal vocalização como um chamado. A este respeito ver Jerusalinsky (2002).

3 Tal termo, inicialmente proposto pelo poeta Paul Eluard, contemporâneo dos pintores surrealistas, é utilizado por Lacan e retomado por Jean Bergès ao falar dos sintomas psicomotores. A esse respeito ver Bergès J. (1988/1997).

${ }^{4}$ Questão mais amplamente desenvolvida em Jerusalinsky (2002).

${ }^{5}$ Tal proposição, realizada em 1948 por Esther Bick (psicanalista discípula de Melanie Klein), inicialmente, fez parte do curso de formação para psicoterapeutas da Clínica Tavistok e, em 1960, foi incorporada ao plano de estudos da Sociedade Britânica de Psicanálise, assim como ao de várias outras sociedades vinculadas à IPA. Posteriormente foram surgindo aplicações clínicas de tal método, baseadas no princípio de que o observador produza um setting favorecedor da interação mãe-bebê.
6 Winnicott (1941). Vale destacar aqui a utilização do termo "observar" no caso do pequeno Hans, justamente um caso de uma criança, em comparação ao termo "escutar", utilizado nos escritos técnicos em que Freud faz referência fundamentalmente à análise de adultos. julietaj@uol.com.br mtberlin@uol.com.br

Recebido em abril/2008. Aceito em junho/2008. 